\title{
Online Course as a Tool to Ensure the Quality of Training Highly Qualified Personnel: Problems and Prospects of Use
}

\author{
Elena V. Korchagina \\ Peter the Great St. Petersburg Polytechnic University \\ St. Petersburg, Russia \\ State Institute of Economics, Finance, Law and Technology \\ (SIEFLT) \\ Gatchina, Russia \\ elena.korchagina@mail.ru
}

\author{
Daria A. Korchagina \\ Honeywell JCS \\ Peter the Great St. Petersburg Polytechnic University \\ St. Petersburg, Russia \\ elena2112201@mail.ru
}

\author{
Natalia D. Strekalova \\ Herzen State Pedagogical University of Russia \\ St. Petersburg, Russia \\ strekalova_spb@mail.ru
}

\begin{abstract}
Nowadays online education is developing rapidly and gradually replacing the traditional format of education. This is due to a number of fundamental advantages of online courses: a geographic accessibility, a convenient training format, and low cost. These advantages allow enterprises to train their specialists at the best universities educational programs without interruption of production process, in the convenient time and place, and also save money for such training. At the same time, statistics show that even on the leading online education platforms, the number of students who successfully complete their online courses is extremely small. This is due to a number of shortcomings and limitations of online learning. The paper presents the results of a study of the Russian student's online learning experience and attitude. The research results allow us to identify the limitations of online learning and offer special measures to overcome them in order to improve the quality of training of highly qualified personnel.
\end{abstract}

Keywords- educational services market; training formats; online learning; online course

\section{INTRODUCTION}

The digitalization of information and communication technologies is rapidly transforming various markets for goods and services. It affects the educational market in all its segments: from preschool to higher. A study conducted in 2017 by a group of analytical and research companies (EastWest Digital News, Public Opinion Fund, Netology Group, Internet Initiatives Development Fund, VB Profiles, comScore, etc.) showed that the Russian market of online education and educational technologies has serious prospects for development. So, the researchers expected a significant increase in the share of the online educational services market on the five-year planning horizon (from $1.1 \%$ in 2016 to $2.6 \%$ in 2021) and more than double market growth in absolute figures (from 20.7 billion rubles in 2016 to 53.3 billion rubles in 2021) [1].

According to researchers, the field of higher education is one of the leading in terms of digitalization. Nowadays it is in third place in terms of online programs penetration $(1.8 \%)$ after additional school $(2.7 \%)$ and additional professional education $(6.7 \%)$. A significant increase in the online segment is also expected in the field of higher education on the fiveyear horizon (to $4.4 \%$ by 2021 ) which means the huge sales increase in this segment.

\section{Statement of THE Research PROBLEM}

Large Russian universities are actively developing online educational products. So, in 2018, 74 training courses were launched by Russian universities on the Coursera online platform. 52 of them are in Russian and 22 are in English. In total, Coursera currently has 275 online courses and specializations in Russian and English developed by Russian universities [2]. Today, 417 online courses of sixteen leading universities of the Russian Federation are posted on the Russian domestic platform called "Open Education". This online platform has eight founders: Moscow State University, Peter the Great St. Petersburg Polytechnic University, St. Petersburg State University, National University of Science and Technology "MISIS", National Research University Higher School of Economics, Moscow Institute of Physics and Technology, Ural Federal University and Saint Petersburg State University of Information Technologies, Mechanics and Optics. In addition to these founders the "Open Education" platform today offers online courses from other Russian universities: Bauman Moscow State Technical University, National Research Nuclear University MEPhI, St. Petersburg Electrotechnical University "LETI", Samara University, 
Tomsk State University, Tyumen industrial University, Tyumen State University and Russian University of Transport [3].

Representation of university courses on an online platform has serious advantages. Firstly, it contributes to a significant geographical expansion of the target audience of the university, providing the opportunity to get access to the educational product for students from the most remote ends Russia and the world. Secondly, the online platform provides the $24 \times 7$ availability of the educational product for the target audience. These advantages lead to an increase in the university's audience, and also in students' loyalty, as well as the popularity and university's brand reputation development in the educational services market.

The highlighted benefits are also relevant for students. Online courses provide an opportunity for students from remote regions to study the best educational programs of the best professors from the best universities, independently determining the mode of study. In addition, the universities' online courses provide students an opportunity to receive not only the necessary knowledge and skills, but also a certificate of attendance at a leading university, which is highly rated by potential employers [4, 5]. However, at the same time, as practice shows, online courses have a number of significant drawbacks. Online education is not interactive; it does not take into account the level of education and the individual characteristics of the student's perception. The format of online education imposes serious restrictions on the duration and the amount of information provided, i.e. the information content of the educational course is reduced. In addition, the online learning format requires the student to be highly motivated, self-discipline, ambition and good time management skills. However some students do not have the listed qualities. Therefore they cannot complete the online course and pass the final exam successfully. In this regard, the student's results and learning outcomes of online courses are generally lower than for traditional ones.

\section{RESEARCH RESULTS AND DISCUSSION}

The subject of our research is the study of the attitude of Russian students to online courses. Having studied their experience of online learning, we were able to identify both its positive and negative sides.

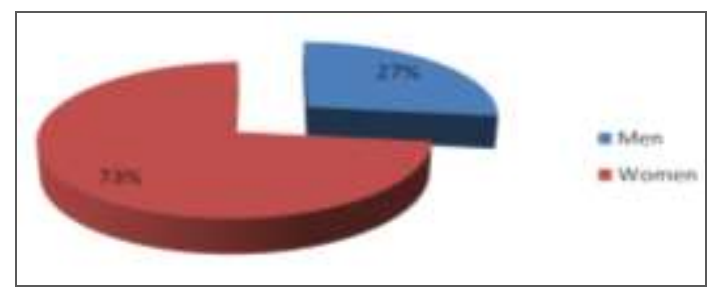

Fig. 1. Distribution of respondents by gender

We interviewed 256 people, of which $27 \%$ were men and $73 \%$ were women (Fig. 1). At the same time, $79 \%$ of the respondents belonged to the age cohort from 18 to 35 years old (Fig. 2). 66\% of the respondents had online learning experience, $34 \%$ did not have such an experience (Fig. 3).

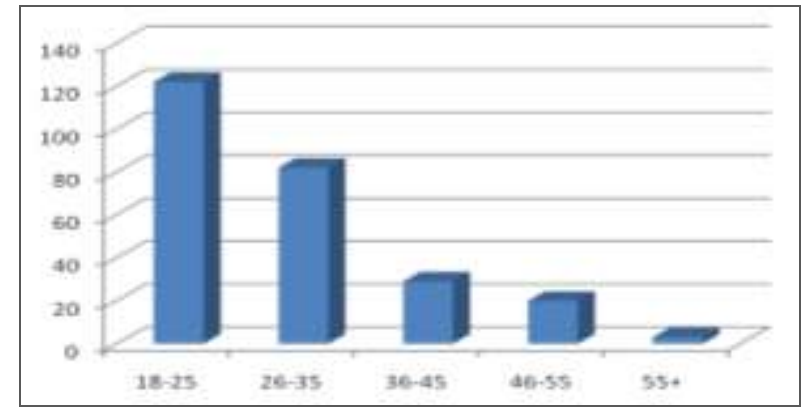

Fig. 2. Distribution of respondents by age

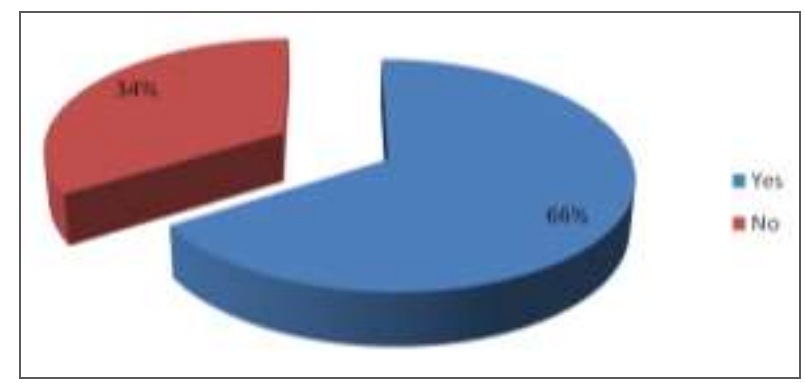

Fig. 3. Distribution of respondents' answers to a question about their online leaning experience

In the group of respondents who had experience of online learning, $81 \%$ reacted to innovation positively, $16 \%$ neutrally and $3 \%$ negatively (Fig. 4).

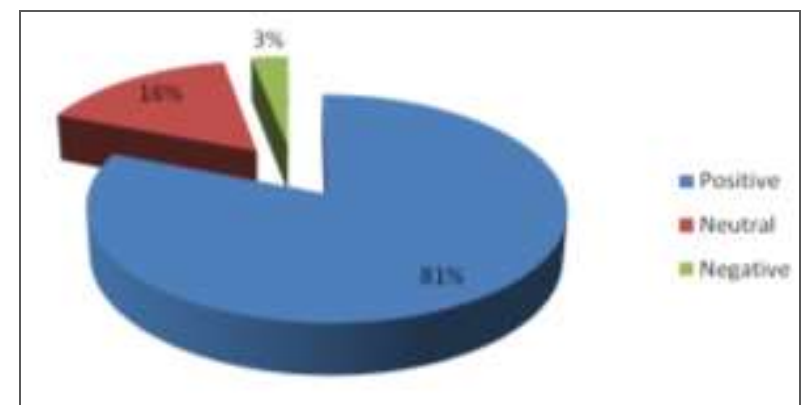

Fig. 4. Distribution of answers of respondents that have online learning experience to a question about their attitude to innovation

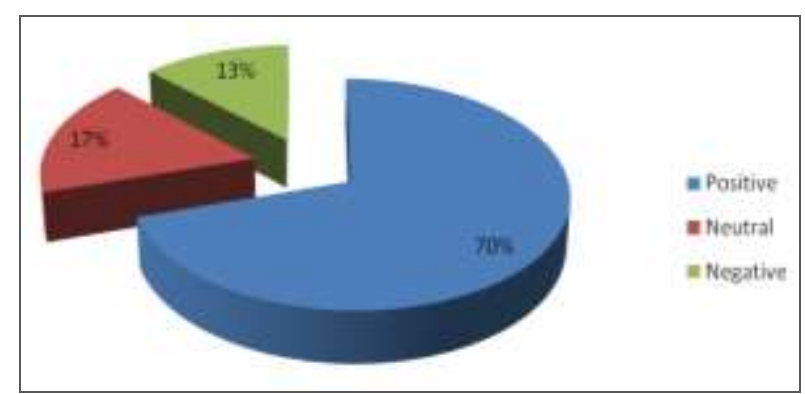

Fig. 5. Distribution of answers of respondents with no online learning experience to a question about their attitude to innovation 
In the group of respondents who did not have online learning experience, $70 \%$ of respondents expressed a positive attitude to innovation, $17 \%$ - neutral, and $13 \%$ - negative (Fig. 5).

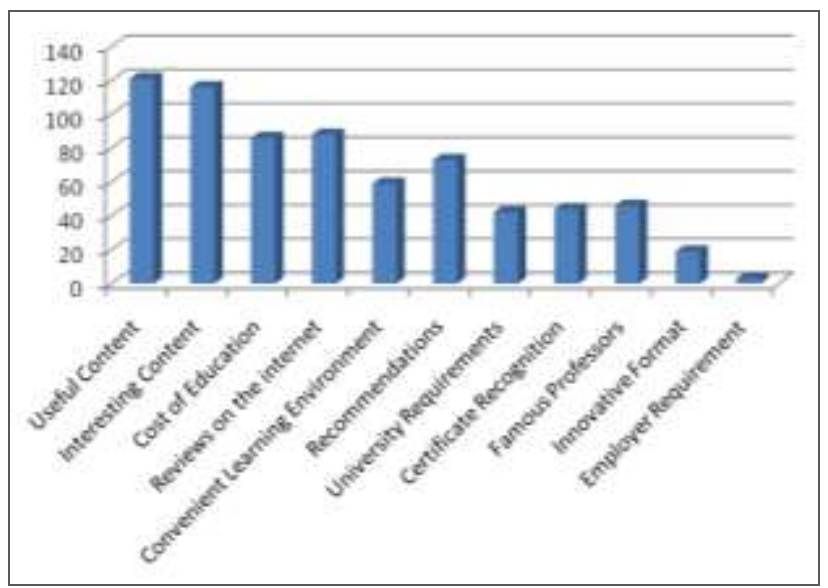

Fig. 6. Online course selection criteria

The criteria for choosing an online course (based on a survey of respondents who had experience of online learning) are presented in Fig. 6. The main ones were the quality of the content (its usefulness and interest), the cost of training, as well as feedback from students who had already attended this course.

The requirements of the university or employer, the certificate recognition, the fame of professors and the innovative format of learning played a much smaller role in the consumer choice of online courses.

It is important to note that the majority of respondents metioned certain difficulties in the process of online learning (Fig. 7). For instance about half of the respondents with online learning experience $(49 \%)$ noted the difficulty in concentrating on the subject of study due to the lack of teacher control; approximately the same number $(47 \%)$ of respondents noted technical problems that arose during learning.

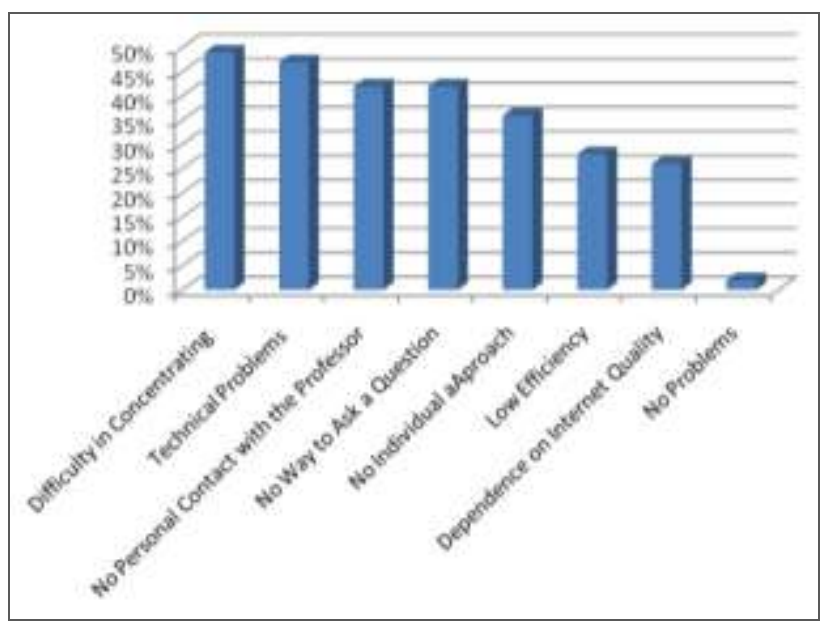

Fig. 7. Respondents difficulties with online courses
Also important negative factors were the lack of personal contact with the teacher, the lack of the ability to ask questions (42\%), and the lack of an individual approach (36\%). In addition, respondents noted low online learning outcomes (28\%) and internet dependence (26\%). Only four people replied that they had no difficulties in completing the online courses. Despite the difficulties described above, the majority of respondents (64\%) were satisfied with online learning (Fig. 8).

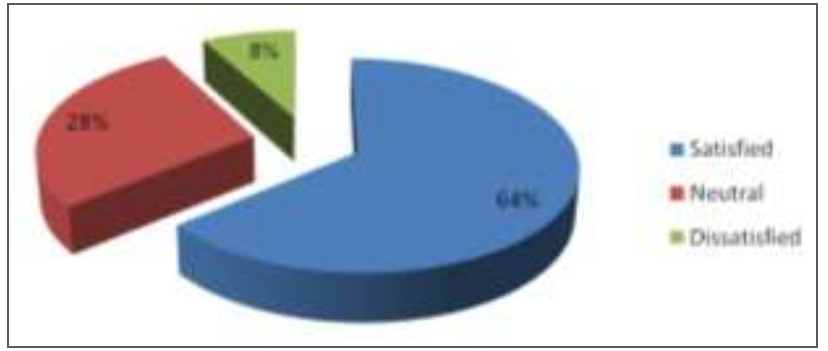

Fig. 8. Online learning satisfaction rating

Among respondents who did not have online learning experience, almost all respondents (97\%) knew about such educational format (Fig. 9). This is not surprising, since the online education market is now not only rapidly developing, but its development is actively discussed in the media and social networks, occupying a significant part of the information space.

Thus, despite the knowledge of the existence of online learning, many respondents refuse to use it. Why is this happening? In order to answer this question, we asked respondents to explain the reasons for not using online courses. The results of the responses are presented in Fig. 10.

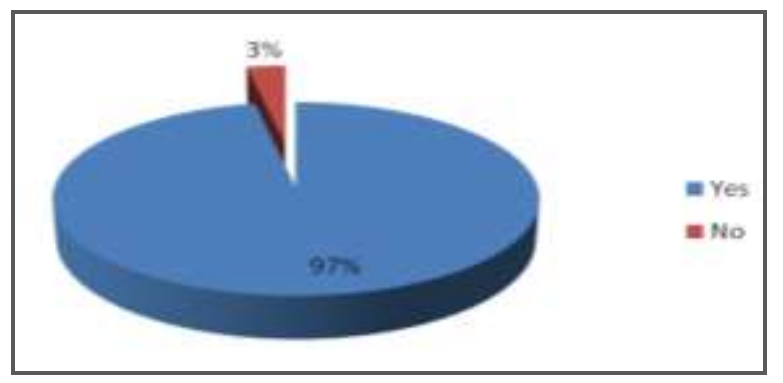

Fig. 9. Distribution of respondents' answers to the question about knowledge of the online learning existence

It turned out that $23 \%$ of respondents do not see the need to use online training; $21 \%$ were unable to find suitable courses; $18 \%$ generally do not trust online learning, $12 \%$ prefer the traditional offline format. Finally, $6 \%$ of respondents simply have difficulties in using the modern educational technologies. 


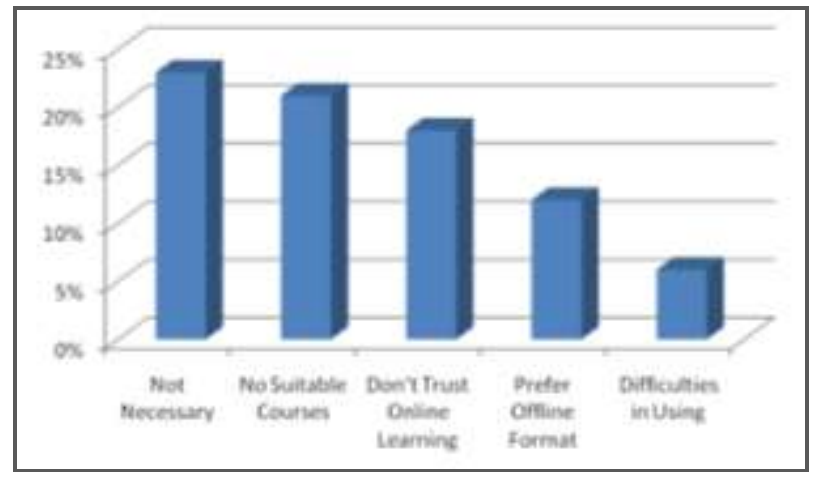

Fig. 10. Distribution of respondents' answers to the question about the reasons for refusing online training

\section{CONCLUSION}

The results of our study showed that in general the modern online learning format satisfies Russian students. However, it has certain disadvantages that must be taken into account when developing this educational format. The main ones include the difficulty of self-organization of work, technical problems and lack of contact with the teacher. The presence of these problems leads to the three key problems. Firstly, many potential users refuse online courses at all. Secondly, a significant part of stidents who started an online course quits studying on the different stages of learning process. Thirdly, the satisfaction of students who successfully completed an online course is reduced.

To overcome these negative consequences, it is possible to offer a set of recommendations. Among the main recommendations for developing online courses and increasing their attractiveness for the target audience, our respondents expressed ideas about introducing the practice of individual work with the teacher (for example, the ability to ask questions and get detailed teachers' explanations on them; receive teachers' feedback on the results of the course assignments; teachers' explanations of students mistakes made in solving problems and cases with giving right solutions, etc.). The second important point is the clarity of the instructions for working with the online course. This will help students evaluate the amount of work in advance and understand the course requirements. And finally, the third is the motivational part. The online course must include a particular explanation on what specific knowledge and skills can be received by student trougth passing each part of the course, and how student can to apply it in the future.

Thus, in addition to high geographical and time accessibility, high-quality and interesting content, well-known teachers and a convenient study format, the online course should include the individual interaction with students, offer effective tools for their motivation, and develop clear instructions for users.

\section{REFERENCES}

[1] The study of the Russian market of online education and educational technologies. URL: https://estars.hse.ru/mirror/pubs/share/211448255 (Access date 01/10/2019). (In Russian)

[2] In 2018, Russian universities launched 74 training courses on the Coursera online platform. URL: https://fulledu.ru/news/5013_2018godu-vuzami-zapuscheno-obuchayuschih.html (Access date 01/10/2019). (In Russian)

[3] National Open Education Platform. URL: https://openedu.ru/ (Date of access 02.21.2019). (In Russian)

[4] Desfonteines L., Korchagina E., Varnaev A., Semenova J. 2019. Organizational culture of trade enterprises in the context of modern demographic challenges and the use of information technology. Proceeding of the 2d International Scientific Conference on Digital Transformation on Manufacturing, Infrastructure and Service (DTMIS2018). IOP Conf. Ser.: Mater. Sci. Eng. Vol. 497. Is.1. 012117. https://doi.org/10.1088/1757-899X/497/1/012117

[5] Korchagina E.V., Shvetsova O.A. 2018. Solving the Problem of Employment for Graduates of Higher Education Institutions: Increasing the Degree of Employers' Participation in the Educational Process. Proceedings of 2018 17th Russian Scientific and Practical Conference on Planning and Teaching Engineering Staff for the Industrial and Economic Complex of the Region, PTES 2018. P. 138-140. 